\title{
Clinical features associated with internal carotid artery occlusion do not correlate with MRA cerebropetal flow measurements
}

\author{
K J van Everdingen, L J Kappelle, C J M Klijn, W P T M Mali, J van der Grond
}

\begin{abstract}
Objectives-The aetiology of clinical symptoms in patients with severe internal carotid artery (ICA) lesions may be thromboembolic or haemodynamic. The purpose was to assess whether changes in cerebropetal blood flow caused by an ICA occlusion have an effect on clinical symptoms and cerebral metabolism.

Methods-Forty three patients with an ICA occlusion who had hemispheric ischaemia (transient ischaemic attack or stroke), retinal ischaemia, or without symptoms, and 34 patients without significant ICA lesions with either hemispheric ischaemia or no symptoms were studied. Magnetic resonance angiography (MRA) was used to investigate total cerebropetal flow (flow in the ICAs plus basilar artery) and the flow in the middle cerebral arteries. Cerebral metabolic changes in the flow territory of the middle cerebral artery were determined with proton MR spectroscopy.
\end{abstract}

Results-Low total cerebropetal flow $(r=-0.15, p<0.05)$ and low middle cerebral artery flow $(r=-0.31, p<0.001)$ were found in patients with an ICA occlusion, but did not correlate with the clinical syndrome. By contrast, patients with prior symptoms of hemispheric ischaemia had decreased cerebral $\mathrm{N}$-acetylaspartate/choline ratios $(r=-0.35, p<0.001)$. However, the presence of an ICA occlusion (and subsequent low flow) did not correlate with low $\mathrm{N}$-acetylaspartate/choline ratios. Conclusion-Neurological deficit caused by (transient) hemispheric ischaemia is associated with low $\mathbf{N}$-acetylaspartate/ choline ratios, whereas prior clinical features are not associated with low cerebropetal blood flow, as measured with MR angiography. As a result, differences in cerebropetal flow cannot explain why patients with similar carotid artery disease experience different neurological features.

(F Neurol Neurosurg Psychiatry 2001;70:333-339)

Keywords: magnetic resonance imaging; cerebral haemodynamics; stroke; metabolism

Patients with a stenosis or occlusion of the internal carotid artery (ICA) may experience transient or permanent ischaemic attacks in the brain or in the retina, but may also remain asymptomatic. ${ }^{1}$ The clinical symptoms in patients with ICA lesions may result from thromboembolism, ${ }^{2-4}$ haemodynamic disturbances $^{15}$ or from a combination of both aetiologies. A severe stenosis or occlusion of the ICA usually causes a decrease in the cerebral perfusion pressure (CPP)..$^{5-8}$ In response to the decreased CPP, autoregulation can lower the intracranial vascular resistance by means of vasodilation to maintain the cerebral blood flow. ${ }^{5}{ }^{9}$ Collateral pathways may also be recruited as a result of the lowered intracranial vascular resistance. ${ }^{10-14}$ Via the anterior communicating artery (AcoA), ${ }^{11}{ }^{14-17}$ and posterior communicating arteries (PcoAs), ${ }^{10-16}$ blood flow from the contralateral ICA and vertebrobasilar system support the perfusion of the affected hemisphere. Via the ophthalmic and leptomeningeal vessels, extracranial blood flow can be deviated intracranially. Additional intracranial redistribution can be established by the leptomeningeal anastomoses as well. When both the autoregulation and the collateral pathways are insufficient, hypoperfusion could lead to transient or permanent ischaemia of the brain or retina. ${ }^{151018}$

Magnetic resonance angiography (MRA) is a non-invasive technique with which the volume of the blood flow in the ICAs, basilar artery (BA), and middle cerebral arteries (MCAs) can be quantified. ${ }^{19-21}$ Arterial occlusive disease has been shown to cause changes in flow volume in these arteries. ${ }^{19}{ }^{22}$ Although measuring blood flow volume in the main cerebropetal arteries provides different information than PET, SPECT, or xenon enhanced CT, MRA gives true values for blood supply to the region at risk, and is an indirect measurement of brain perfusion. It can be expected that a decrease in flow volume in, for example, the MCA will have an effect on the perfusion of the MCA flow territory which may result in a drop in the local cerebral blood flow or an increase in regional oxygen extraction fraction, possibly resulting in focal ischaemia.

With proton magnetic resonance spectroscopy ( $\left.{ }^{1} \mathrm{H}-\mathrm{MRS}\right)$, the concentrations of $\mathrm{N}$-acetylaspartate (NAA) and choline (Cho) in the brain parenchyma can be determined. $\mathrm{N}$-Acetylaspartate is almost exclusively located in neurons. ${ }^{23}$ Although the NAA concentration is closely related to the neuronal density, its function remains uncertain. A decrease in NAA is presumed to be characteristic for neuronal loss $s^{23-26}$ or for decreased neuronal functionality. ${ }^{27}{ }^{28}$ Choline is used in the synthesis of acetylcholine and in phospholipid biosynthesis. An increase in choline is presumed to be the 
result of membrane degradation - for example, in response to ischaemia. ${ }^{29}$ Decreases in the NAA/Cho ratios in patients with symptomatic carotid artery disease have been shown to be indicative for ischaemic cerebral damage. ${ }^{29-32}$

It is not known why similar lesions in the ICA cause different clinical features. The purpose of this study was to investigate whether different clinical and metabolic features are associated with specific changes in cerebropetal blood flow. We therefore investigated alterations in cerebral metabolism, cerebropetal blood flow and intracranial collateral flow patterns in patients with a unilateral occlusion of the ICA, who either had hemispheric ischaemia (transient ichaemic attack or stroke), retinal ischaemia, or who had no symptoms. These patients were compared with symptomatic patients without haemodynamically significant ICA lesions, and with asymptomatic patients without ICA occlusive disease.

\section{Patients and methods}

The study patients comprised 43 with an ICA occlusion resulting in signs or symptoms of ipsilateral hemispheric ischaemia, ipsilateral ocular ischaemia, or no symptoms, and 34 patients without significant ICA lesions, with or without signs or symptoms of ipsilateral hemispheric ischaemia. All symptomatic patients had had their latest clinical symptoms during the previous 6 months (mean time between latest symptoms and MRI 76 days (SD 49) days). Furthermore, no patients were investigated within the first 2 weeks after onset of symptoms. All patients underwent the same MRI, MRA, and single voxel ${ }^{1} \mathrm{H}-\mathrm{MRS}$ protocol between May 1995 and March 1998. Twenty four patients with an ICA occlusion had signs or symptoms of hemispheric ischaemia, of whom 10 patients had had transient ischaemic attacks and 14 patients had had a minor stroke (mean age 60 (SD 8) years, 21 men, three women). Twelve patients with an ICA occlusion had signs or symptoms of ocular ischaemia, including 10 patients with transient monocular blindness and two patients with chronic ocular ischaemia (mean age 62 (SD 12) years, 10 men, two women). Seven patients with an ICA occlusion were asymptomatic (mean age 67 (SD 10) years, all men). Nine of the 34 patients without haemodynamically significant ICA lesions $\left(<70 \%{ }^{33}\right)$ had had signs or symptoms of hemispheric ischaemia (transient ischaemic attack $(n=3)$ or minor stroke $(n=6)$; mean age 66 (SD 12) years, eight men, one woman, ICA stenosis ipsilateral side 56 (SD 9) $\%$, ICA stenosis contralateral side 14 (SD 17)\%). The remaining 25 patients (mean age 58 (SD 12) years, 16 men, nine women) had no history of ischaemic neurological deficits, had no abnormalities on the MRI of the brain, and had normal cerebropetal arteries on MRA. The ${ }^{1} \mathrm{H}-\mathrm{MRS}$ data and the flow data of the MCAs of these patients were obtained by averaging the data of the left and right side of each patient.

Patients with major disabilities (Rankin scale $>3$ ); those with an ipsilateral or contralateral ICA stenosis of $70-99 \%$; those with bilaterally occluded ICAs; patients with a combina- tion of hemispheric and retinal symptoms; those with symptoms of ischaemia in the vertebrobasilar flow territory; and those with clinical symptoms based on intracranial MCA stenosis, vasculitis, or atrial fibrillation were not included.

The severity of the ICA lesions of all symptomatic patients was investigated with intra-arterial digital subtraction angiography (iaDSA). The asymptomatic patients with an ICA occlusion were investigated with duplex ultrasonography, according to a previously published protocol, ${ }^{34}$ after which the occlusion was confirmed with MRA. The 25 asymptomatic patients without an ICA occlusion underwent only MRA to rule out significant carotid disease. Written informed consent was acquired from all patients. The study protocol was approved by the human research committee of our hospital.

MRI, ${ }^{1} \mathrm{H}-\mathrm{MRS}$, AND MRA

All MRI, ${ }^{1} \mathrm{H}-\mathrm{MRS}$, and MRA investigations were performed on a Philips Gyroscan ACS-NT 15 whole body system operating at 1.5 Tesla (Philips Medical Systems, Best, The Netherlands). Previous studies have described the MR techniques applied in more detail. ${ }^{213536}$ The MRI examinations consisted of a sagittal $\mathrm{T} 1$ weighted spin echo sequence (repetition time (TR)/echo time (TE) 545/ 15 $\mathrm{ms}$ ) and a transaxial double echo T2 weighted spin echo sequence (TR/TE 2000/20 ms and $2000 / 100 \mathrm{~ms}$ ). Infarcts were either classified as territorial infarcts (including the lacunar infarcts) or as border zone infarcts. ${ }^{37} 38$

To visualise the circle of Willis, 50 slices were obtained with a 3D MRA time of flight (TOF) technique (TR/TE $31 / 6.9 \mathrm{~ms}$ ). These images were reconstructed in three directions with a maximum intensity projection (MIP) algorithm. The direction of blood flow in the circle of Willis was measured with two 2D phase contrast methods of which one was phase encoded in the anterior-posterior direction and another in the left-right direction (TR/TE $16 / 9.1 \mathrm{~ms}$, velocity sensitivity $\left.\left(\mathrm{V}_{\text {enc }}\right) 40 \mathrm{~cm} / \mathrm{s}\right)$. Two collateral flow pathways were studied: cross flow through the ACoA, and posterior-toanterior flow through the ipsilateral PCoA. The presence of collateral flow through these pathways was independently evaluated by two of us (KJvE, JvdG) and discrepancies were reevaluated in a consensus reading.

All MRA volume flow measurements were performed with a non-triggered $2 \mathrm{D}$ phase contrast technique. ${ }^{192136}$ Flow measurements through the ICAs and BA were obtained at the level of the skull base (TR/TE16/9 ms, eight signals acquired, $V_{\text {enc }} 100 \mathrm{~cm} / \mathrm{s}$ ). Total cerebropetal blood flow was calculated by cumulating the flow through both ICAs and the basilar artery. In addition, two flow measurement slices were positioned perpendicular to the left and right MCA (TR/TE $17 / 10 \mathrm{~ms}, 24$ signals acquired, $V_{\text {enc }} 70 \mathrm{~cm} / \mathrm{s}$ ). Volume flow values were obtained by integrating across manually drawn regions of interest (ROIs) enclosing the vessel lumen. 
Table 1 Volume flow ( $\mathrm{ml} / \mathrm{min}),{ }^{1} \mathrm{H}-\mathrm{MRS}$ results, and prevalence of infarcts

\begin{tabular}{|c|c|c|c|c|c|c|c|c|c|c|}
\hline $\begin{array}{l}\text { Group number } \\
\text { ICA occlusion? } \\
\text { Symptoms } \\
n\end{array}$ & $\begin{array}{l}1 \\
\text { Yes } \\
\text { Hemispheri } \\
24\end{array}$ & & $\begin{array}{l}2 \\
\text { Yes } \\
\text { Retinal } \\
12\end{array}$ & & $\begin{array}{l}3 \\
\text { Yes } \\
\text { None } \\
7\end{array}$ & & $\begin{array}{l}4 \\
\text { No } \\
\text { Hemispheric } \\
9\end{array}$ & & $\begin{array}{l}5 \\
\text { No } \\
\text { None } \\
25\end{array}$ & \\
\hline MRA volume flow & \multicolumn{2}{|c|}{ Median (\%) percentiles } & \multicolumn{2}{|c|}{ Median (\%) percentiles } & \multicolumn{2}{|c|}{ Median (\%) percentiles } & \multicolumn{2}{|c|}{ Median (\%) percentiles } & \multicolumn{2}{|c|}{ Median percentiles } \\
\hline Total cerebropetal flow & $498(92 \%)$ & $(396-568)$ & $438(81 \%)$ & $(404-461)$ & $406(75 \%)$ & $(371-492)$ & $546(101 \%)$ & $(483-606)$ & 543 & $(450-609)$ \\
\hline MCA ipsilateral & $72(67 \%)$ & $(56-89)$ & $93(77 \%)$ & $(81-104)$ & $62(51 \%)$ & $(51-85)$ & $108(89 \%)$ & $(71-140)$ & 121 & $(112-147)$ \\
\hline MCA contralateral & $82(59 \%)$ & $(70-107)$ & $100(83 \%)$ & $(82-119)$ & $98(81 \%)$ & $(69-111)$ & $138(114 \%)$ & $(98-154)$ & 121 & $(112-147)$ \\
\hline \multicolumn{11}{|l|}{ NAA/Cho ratio: } \\
\hline Ipsilateral side & $1.52(82 \%)$ & $(1.42-1.69)$ & $1.71(92 \%)$ & $(1.69-1.84)$ & $1.71(92 \%)$ & $(1.69-1.87)$ & $1.57(84 \%)$ & $(1.45-1.76)$ & 1.86 & $(1.76-2.04)$ \\
\hline Contralateral side & $1.77(95 \%)$ & $(1.56-2.00)$ & $1.85(99 \%)$ & $(1.81-1.94)$ & $1.83(98 \%)$ & $(1.72-1.93)$ & $1.80(97 \%)$ & $(1.70-1.91)$ & 1.86 & $(1.76-2.04)$ \\
\hline Infarcts ipsilateral side & $n$ & Prevalence & $n$ & Prevalence & $n$ & Prevalence & $n$ & Prevalence & $n$ & Prevalence \\
\hline Territorial & 10 & $42 \%$ & 2 & $17 \%$ & 0 & $0 \%$ & 5 & $50 \%$ & 0 & $0 \%$ \\
\hline Border zone & 7 & $29 \%$ & 2 & $17 \%$ & 0 & $0 \%$ & 3 & $30 \%$ & 0 & $0 \%$ \\
\hline Both & 4 & $17 \%$ & 0 & $0 \%$ & 0 & $0 \%$ & 1 & $10 \%$ & 0 & $0 \%$ \\
\hline
\end{tabular}

Patients are grouped by the presence or absence of an ICA occlusion, and by the presence or absence of symptoms. Flow and ${ }^{1} \mathrm{HMRS}$ data are expressed as median, as a percentage of the median in group 5 , and as the 25 th and 75 th percentile. Total cerebropetal flow is calculated by summing the flow in both ICAs and the BA. Prevalence of territorial infarcts (including lacunar), border zone infarcts or both type of infarcts in the ipsilateral hemisphere of the patients.

The ${ }^{1} \mathrm{H}-\mathrm{MRS}$ investigations were performed with a single voxel technique. Two volumes of interest (VOIs) of equal size were selected in the centrum semiovale of each patient, one in the symptomatic hemisphere and another in the asymptomatic hemisphere. These VOIs were chosen from the T2 weighted transaxial MR images and primarily contained white matter. The white matter in the centrum semiovale is particularly vulnerable to hypoperfusion as this area is a so-called border zone area, located in the distal part of the deep and superficial branches of the middle cerebral artery. This area is likely to be one of the first to have ischaemic damage when blood flow decreases. ${ }^{39}$ The dimensions of the selected VOIs were kept equal in both hemispheres and were typically $70 \mathrm{~mm}$ and $35 \mathrm{~mm}$ in anteriorposterior and left-right directions. Regions containing subcutaneous lipid were excluded. Special care was taken to position these VOIs away from grey/white matter hyperintensities and VOI size was reduced if necessary. After selection of a VOI, the 90 degree pulse length was determined. To minimise eddy currents and to maximise the water echo signal, localised spectroscopy was first performed without water suppression for adjustments of the gradients ("gradient tuning"). This was followed by localised automatic shimming of the VOI, resulting typically in a water resonance line width of $6 \mathrm{~Hz}$ (full width at half maximum) or less. Water suppression was performed by selective excitation $(60 \mathrm{~Hz}$ band width), followed by a spoiler gradient. A double spin echo point resolved spectroscopy (PRESS) sequence was used for VOI localisation. ${ }^{40} 41$ Each measurement was performed with a repetition time of $2000 \mathrm{~ms}$, an echo time of $136 \mathrm{~ms}, 2048$ time domain data points, 4000 $\mathrm{Hz}$ spectral width, and 64 or 128 signals acquired. After zero filling to 4096 data points, gaussian multiplication of $5 \mathrm{~Hz}$, exponential multiplication of $-4 \mathrm{~Hz}$ (line broadening), Fourier transformation and linear baseline correction, total choline (Cho) and $\mathrm{N}$-acetylaspartate (NAA, referenced at 2.01 ppm) peaks were identified by their chemical shifts. Signal intensities were determined by peak height measurements. As we were unable to calculate absolute metabolic concentrations, the metabolic data were expressed as ratios between the peak intensities of NAA and Cho. Total study time per patient was about 40 minutes, from which 10 minutes were used for MRI, 20 minutes for MRA, and 10 minutes for ${ }^{1} \mathrm{H}-\mathrm{MRS}$.

STATISTICAL ANALYSIS

Correlations between ICA lesions or previous clinical features versus cerebropetal blood flow and cerebral metabolism were investigated with logistic regression analysis. In addition, subanalyses of changes in flow or ${ }^{1} \mathrm{H}-\mathrm{MRS}$ results between the groups were performed with the non-parametric Wilcoxon rank sum $W$ test. This test was used because of differences in the sample sizes and was performed after using a Kruskal Wallis $H$ test to compare the flow data and NAA/Cho ratios by groups. All flow data and NAA/Cho ratios were expressed as mean and $95 \%$ confidence intervals (95\% CIs). Statistical significance was corrected for repeated measures (Dunn's multiple comparison procedure) and $p$ values were considered significant at $p<0.05$. The $\chi^{2}$ test was used to compare the collateral flow patterns between the patients with an ICA occlusion.

\section{Results}

To investigate the correlation between ICA lesions or previous clinical features with cerebropetal blood flow and cerebral metabolism, we analysed the entire patient group by logistic regression analysis. This analysis showed a significant correlation between the presence or absence of an ICA occlusion and total cerebropetal flow $(r=-0.15, \mathrm{p}<0.05)$ and between the presence or absence of an ICA occlusion and the flow in the ipsilateral MCA $(r=-0.31, \mathrm{p}<0.001)$. No such correlation was found between the presence or absence of an ICA occlusion and the ipsilateral NAA/Cho ratio. Logistic regression analysis showed no significant correlation between the presence or absence of previous symptoms of hemispheric ischaemia and total cerebropetal flow or flow in the MCAs. However, a significant correlation was found between the presence or absence of previous symptoms of hemispheric ischaemia and the ipsilateral NAA/Cho ratio $(r=-0.35$, $\mathrm{p}<0.001$ ). 
A

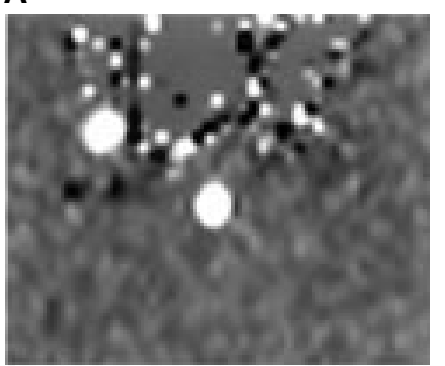

B
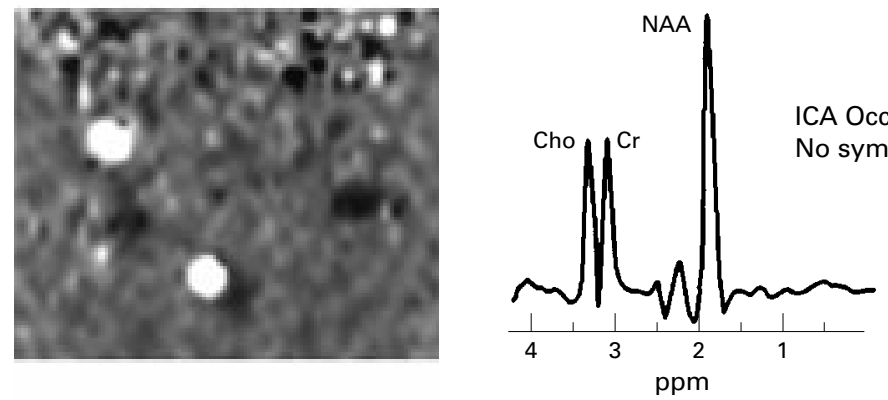

C
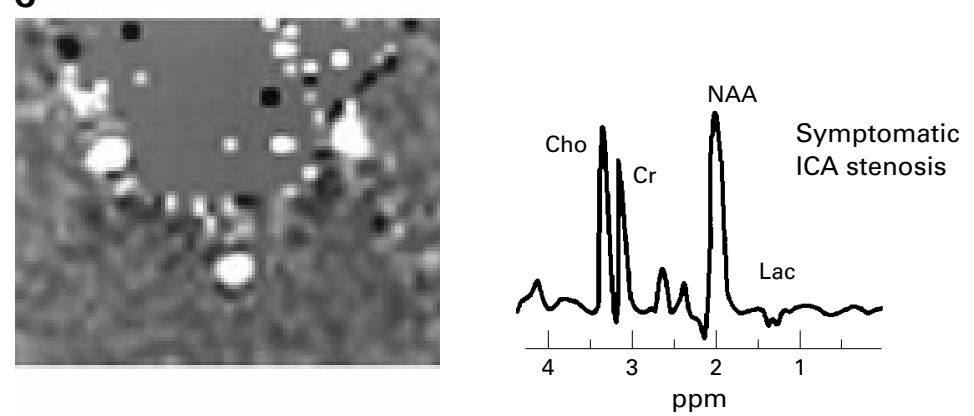

D

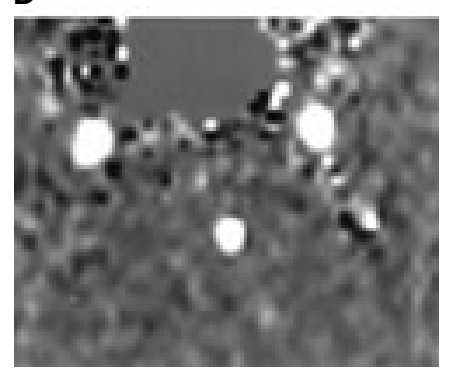

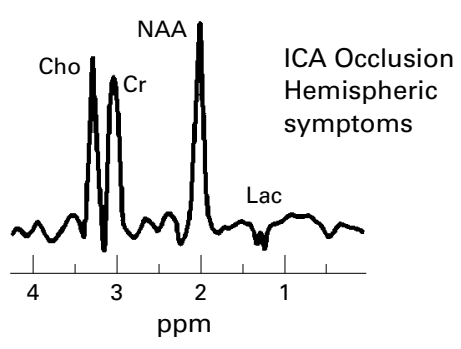

CA Occlusion No symptoms

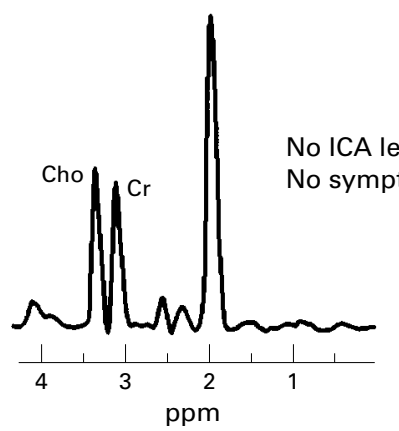

Figure 1 MRA slice for quantitative flow measurements through the ICAs and BA and ${ }^{1} H-M R$ spectra of non-infarcted white matter areas. Peaks show the relative concentrations of $\mathrm{N}$-acetyl aspartate (NAA) and choline (Cho). Creatine (Cr) and lactate concentrations were not evaluated. (A) A 58 year old woman who had a stoke ipsilateral of her left sided ICA occlusion. Flows in the contralateral ICA and BA were 193 and $236 \mathrm{ml} / \mathrm{min}$, respectively. The ipsilateral NAA/Cho ratio was decreased. (B) 78 year old asymptomatic man with a left sided ICA occlusion. Flow in the contralateral ICA and BA was 359 and $225 \mathrm{ml} / \mathrm{min}$ respectively, the ipsilateral NAA/Cho ratio was not significantly decreased. (C) A 63 year old man with a left sided symptomatic ICA stenosis of $50 \%$. Flow in the

ipsilateral ICA, contralateral ICA, and BA was $207 \mathrm{ml} / \mathrm{min}, 213 \mathrm{ml} / \mathrm{min}$, and $196 \mathrm{ml} / \mathrm{min}$, respectively. The ipsilateral $N A A$ /Cho ratio was decreased. (D) $M R A$ flow image and $M R$ spectrum of an asymptomatic patient without ICA lesions.

To analyze the correlations between ICA lesions and the clinical features versus the cerebropetal flow and hemispheric NAA/Cho ratios in more detail, patients were put into five groups according to their ICA lesions and prior clinical symptoms. These subanalyses were
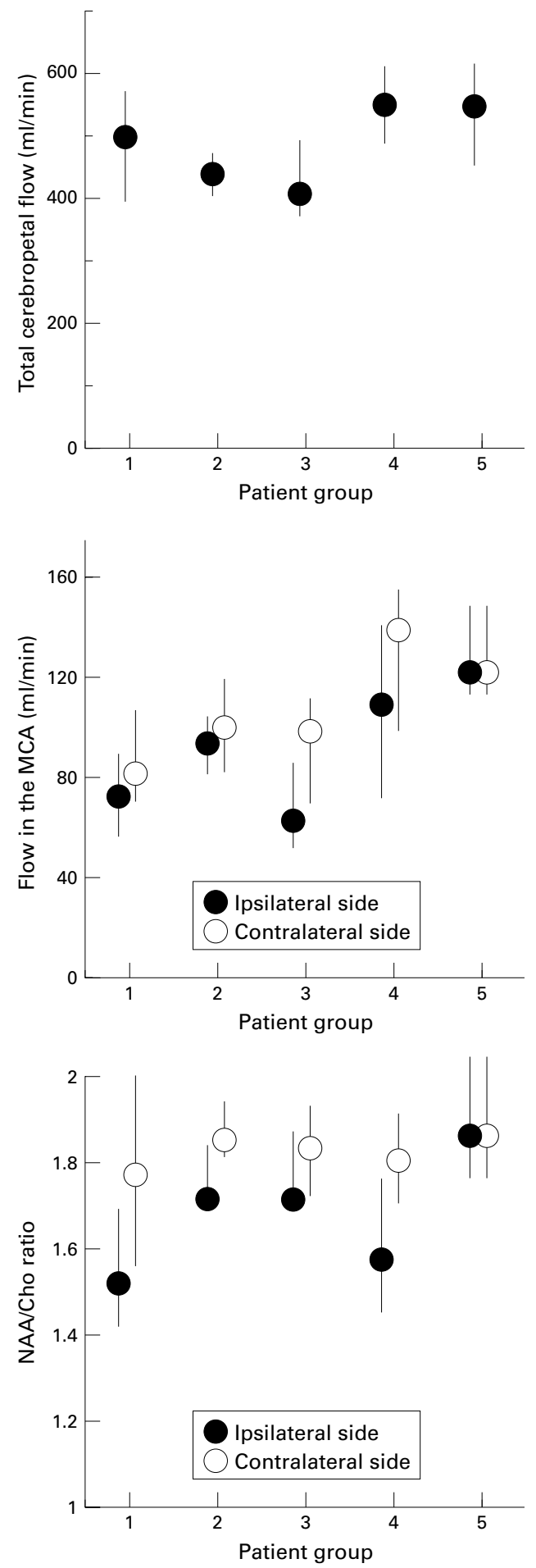

Figure 2 (A) Total cerebropetal flow, (B) flow in the $M C A$ s and (C) NAA/Cho ratios in the five groups of patients. Group 1: ICA occlusion +hemispheric ischaemia. Group 2: ICA occlusion + retinal ischaemia. Group 3: ICA occlusion, no symptoms. Group 4: <70\% ICA stenosis themispheric ischaemia. Group 5: no ICA occlusive disease, no symptoms. Data are expressed as median and 25 th and 75 th percentiles.

performed with the Wilcoxon rank sum $W$ test. The results of the MRA volume flow measurements and ${ }^{1} \mathrm{H}-\mathrm{MRS}$ of these five groups are summarised in table 1 . Age $(p=0.16$, analysis of variance (ANOVA) and sex $\left(p=0.12, \chi^{2}\right)$ did not vary significantly between the five groups. Typical ${ }^{1} \mathrm{H}-\mathrm{MRS}$ results and MRA quantitative 
Table 2 Collateral flow patterns in patients with ICA occlusions

\begin{tabular}{lllll}
\hline $\begin{array}{l}\text { Group number } \\
\text { Type of symptoms }\end{array}$ & $\begin{array}{l}1 \\
\text { Hemispheric } \\
24\end{array}$ & $\begin{array}{l}2 \\
\text { Retinal } \\
12\end{array}$ & $\begin{array}{l}3 \\
\text { None } \\
7\end{array}$ & \\
\hline Collateral flow via ACoA & $63 \%$ & $75 \%$ & $86 \%$ & $\chi^{2} \mathrm{p}=0.5$ \\
Collateral flow via PCoA & $33 \%$ & $42 \%$ & $43 \%$ & $\chi^{2} \mathrm{p}=0.8$ \\
\hline
\end{tabular}

flow measurements of four of these patients are shown in fig 1 .

Firstly, we compared the flow and metabolic results of patients with similar clinical features but with different carotid diseases (comparisons between patients with hemispheric ischaemia: groups 1 and 4 ; and between patients without hemispheric ischaemia: groups 2, 3, and 5). In patients with hemispheric ischaemia, total cerebropetal did not significantly differ (groups $1 v$ group 4, fig $2 \mathrm{~A}$ ). The median flow in the MCAs was $23 \%$ lower in patients with an ICA occlusion (group 1) than in patients with a $<70 \%$ ICA stenosis (group 4), but this did not reach statistical significance (fig $2 \mathrm{~B}$ ). This might be the result of the small sample size of group 4 (type II error). The prevalence of either territorial infarcts or border zone infarcts was almost the same for both groups (table 1). In the patients without hemispheric ischaemia, total cerebropetal flow $(\mathrm{p}<0.01)$, and flow in the ipsilateral $(\mathrm{p}<0.001)$ and contralateral MCA $(p<0.01)$ was significantly lower in patients with an ICA occlusion than in patients with normal ICAs (group $2 v$ group 5: total flow, ipsilateral MCA, contralateral MCA respectively: $19 \%, 25 \%$, and $17 \%$ decrease in median flow; group $3 v$ group 5: $23 \%, 49 \%$ and $19 \%$ decrease in median flow (table 1, fig $2 \mathrm{~A}$ and $\mathrm{B}$ ).

The NAA/Cho ratios of patients with hemispheric ischaemia (groups 1 and 4) were in the same range, independently of the severity of the ICA lesions (fig $2 \mathrm{C}$ ). Similarly, patients without hemispheric ischaemia (groups 2, 3, and 5) all had NAA/Cho ratios that were within the same range. However, the ipsilateral NAA/Cho ratio of patients with hemispheric ischaemia (groups 1 and 4) was significantly lower than the ipsilateral NAA/Cho ratio of patients without the ischaemia (groups 2, 3, and 5, $\mathrm{p}<0.001)$. The NAA/Cho ratios of the contralateral (asymptomatic) hemispheres were within the same range in all groups.

Secondly, we compared the metabolic and flow results of patients with similar carotid diseases but with different clinical features (comparisons among patients with an ICA occlusion: groups 1,2, and 3, and among patients without haemodynamically significant ${ }^{33}$ ICA lesions: groups 4 and 5). No significant differences in any of the flow indices were found whether patients with an ICA occlusion had signs or symptoms of hemispheric ischaemia (group 1), retinal ischaemia (group 2), or no symptoms (group 3, Wilcoxon rank sum $W$ test). In addition, the prevalence of collateral flow via the ACoA $\left(p=0.5, \chi^{2}\right)$ or PCoA $(p=0.8$, $\chi^{2}$ ) did not significantly differ between these three groups of patients (table 2). When groups 2 and 3 were combined, again the prevalence of collateral flow via the ACoA or PCoA did not significantly differ from group $1(\mathrm{p}=0.4, \mathrm{p}=0.8$, $\left.\chi^{2}\right)$. Similarly, in patients without an ICA occlusion, no significant differences in flow were found whether these patients had had signs or symptoms of hemispheric ischaemia (group 4) or whether they were asymptomatic (group 5). However, the patients with an ICA occlusion (groups 1, 2, and 3) had significantly lower total cerebropetal flow $(\mathrm{p}<0.05)$ and ipsilateral MCA flow ( $p<0.001$, Wilcoxon rank sum $W$ test) than the patients without an ICA occlusion (groups 4 and 5). By contrast, in the presence of an ICA occlusion, patients with hemispheric ischaemia (group 1) had lower ipsilateral NAA/Cho ratios than patients with retinal ischaemia (group 2, $\mathrm{p}<0.01$, Wilcoxon rank sum $W$ test) or asymptomatic patients (group 3). The last was not significant, probably because of the small sample size of group 3 (type II error). Similarly, in the absence of an ICA occlusion, patients with hemispheric symptoms (group 4) had lower ipsilateral NAA/Cho ratios than the asymptomatic patients (group 5, p $<0.001$, Wilcoxon rank sum $W$ test).

\section{Discussion}

The most important finding of this study was that we found no correlation between the occurrence of hemispheric symptoms and changes in total cerebropetal flow and MCA flow.

On the other hand, a strong relation was found between the occurrence of hemispheric symptoms and the NAA/Cho ratios in noninfarcted areas in symptomatic hemispheres.

Our MRA results show that total cerebropetal flow and flow in the ipsilateral MCA was significantly decreased in case of ICA occlusion ( $8 \%-25 \%$ decrease in flow in comparison with healthy subjects), independently whether the patients were symptomatic or not. By contrast, total cerebropetal flow and MCA flow were in the normal range in patients with neurological deficit associated with an ICA stenosis of $<70 \%$ (group 4). Apparently, chronically decreased cerebropetal flow seems not to be associated with prior clinical symptoms. Rather, a reduction in cerebropetal flow seems to be correlated with the presence of severe ICA lesions. These changes in flow resulting from ICA disease are in agreement with previous MRA quantitative flow studies in patients with ICA stenoses ${ }^{42-48}$ or occlusions. ${ }^{22}{ }^{35} \mathrm{Al}-$ though these prior MRA studies did not take the various clinical syndromes into account, ${ }^{22} 3542-444647$ the current study shows that this would not have affected their results.

There are several possibilities to explain why we found no correlation between the volume flow and the clinical syndrome. In cases of an ICA occlusion, patients may have notable compensatory flow via the ophthalmic and leptomeningeal vessels, which we were unable to investigate. As a result, our measurements of the total cerebropetal blood flow, cumulating the flow in the ICAs and BA should be interpreted with care as a significant part of the cerebropetal blood flow may be supplied via these pathways. However, our previous work 
did not show any increase in flow via the external carotid arteries in patients with a unilateral or bilateral ICA occlusion, ${ }^{22}$ indicating that the volume of the collateral flow via the external carotid artery branches is limited. In addition, if the ophthalmic arteries contributed significantly to the cerebral blood flow, a $29 \%-43 \%$ drop in flow via the MCAs as we found in our study would be unlikely. Low flow in the MCAs, on the other hand, may be the result of intracranial collateral flow via leptomeningeal vessels. Via these vessels, part of the MCA flow territories may be supplied by the other cerebral arteries, resulting in a lower demand of flow via the MCAs. Furthermore, it is also possible that patients with low cerebropetal flow remain asymptomatic because there oxygen utilisation has been increased, and that these patients continue to be asymptomatic as long as no thromboembolic events occur.

Previous MRA studies that investigated intracranial collateral flow patterns in patients with an ICA occlusion found an increased number of border zone infarcts when collateral flow via the $\mathrm{AcoA}^{11}$ or ipsilateral $\operatorname{PcoA}^{10}$ was absent. These results indicate that inadequate collateral flow may result in hemispheric ischaemia. However, our study found no association between the clinical syndrome and the pattern of collateral flow via the circle of Willis. Perhaps the similarity in intracranial collateral flow patterns in the investigated group of patients with an ICA occlusion reflects a selection of those who survived, whereas others without sufficient collateral flow may have had a severe stroke when the ICA became occluded. ${ }^{49}$ Several studies have shown that the compensatory mechanisms for chronic cerebral hypoperfusion improve over time. With transcranial Doppler, Widder et a ${ }^{0}$ showed that the $\mathrm{CO}_{2}$ reactivity can improve up to 18 months after a cerebral ischaemic event, and Derdeyn et $a \bar{l}^{11}$ found an improvement in the oxygen extraction fraction even at 5 years after stroke. To test whether haemodynamic improvement also occurred in our patient groups, we have analyzed the relation between the time interval (between the symptoms and MRI) and flow or metabolism for each symptomatic group. No such relations were found.

Decreased NAA/Cho ratios were found in patients with symptoms of hemispheric ischaemia, irrespective of the ICA lesion, total cerebropetal flow, or MCA flow. As we found that these abnormal ${ }^{1} \mathrm{H}$-MRS findings appear in areas that look normal on $\mathrm{T} 2$ weighted images, our results indicate that these patients may have cerebral damage or continued abnormality in the cerebral metabolism outside infarcted areas, perhaps as a result of the ischaemic insult. Another explanation could be that numerous (thromboembolic) microinfarcts that remain invisible on T2 weighted MRI are present in these areas. ${ }^{52}$

Several studies using PET have shown a strong relation between the oxygen extraction fraction and the presence of clinical symptoms. ${ }^{53}$ Particularly the prevalence of cerebral stroke is associated with a high oxygen extrac- tion fraction. If the NAA/Cho ratio is a reliable marker for cerebral metabolism in these non-infarcted areas, it is likely that the changes in the NAA/Cho ratios have the same origin as increased oxygen extraction fraction and decreased oxygen metabolism, as measured with PET. $^{5354}$ The blood flow volume in the MCA as measured with MRA, on the other hand, did not show a correlation with clinical symptoms.

The accuracy and reproducibility of MRA quantitative flow measurements of the main cerebropetal arteries have been well established, both in animal ${ }^{20}$ and human studies. $^{192155}$ Potential artifacts of the applied ungated technique include a decreased reproducibility in the presence of pulsatile flow and decreased accuracy because of partial volume effects. However, previous in vitro studies found a high correlation between the volume flow measured by ungated $2 \mathrm{D}$ phase contrast MRA and the actual flow, both in constant ${ }^{5657}$ and pulsatile flow patterns. ${ }^{58}$ In weakly pulsatile monophasic flow such as in the carotid arteries, ungated $2 \mathrm{D}$ phase contrast MRA has been shown to have a less than $1 \%$ error. ${ }^{36}$ Partial volume may play a part in the flow measurements in small vessels. However, the ROIs in our MCA flow measurements were typically $20-30$ voxels in size, which is well above the minimum of 16 voxels necessary to obtain a measurement accuracy of $10 \% .^{59}$

In summary, this study shows a positive correlation between the presence of an ICA occlusion and decreased cerebropetal flow and between decreased NAA/Cho ratios and prior clinical symptoms caused by hemispheric ischaemia. However, differences in cerebropetal flow and intracranial collateral flow patterns cannot explain why occlusion of an ICA causes retinal ischaemia in one patient and hemispheric ischaemia in the other, whereas some patients remain free of symptoms.

The presented study was supported by the Netherlands Heart Foundation (grants D $94-012$ and 94.085). JvdG is clinical investigator of the Netherlands Heart Foundation.

1 Klijn CJM, Kappelle LJ, Tulleken CAF, et al. Symptomatic carotid artery occlusion. A reappraisal of hemodynamic factors. Stroke 1997;28:2084-93.

2 Georgiadis D, Grosset DG, Lees KR. Transhemispheric passage of microemboli in patients with unilateral internal carotid artery occlusion. Stroke 1993;24:1664-6.

3 Finklestein SP, Kleinman GM, Cuneo R, et al. Delayed stroke following carotid occlusion. Neurology 1980;30:848.

4 Barnett HJ, Peerless SJ, Kaufmann JC. Stump on internal carotid artery: a source for further cerebral embolic ischemia. Stroke 1978;9:448-56.

5 Powers WJ. Cerebral hemodynamics in ischemic cerebrovascular disease. Ann Neurol 1991;29:231-40.

6 Leblanc R, Yamamoto YL, Tyler JL, et al. Hemodynamic and metabolic effects of extracranial carotid disease. Can $\mathcal{F}$ Neurol Sci 1989;16:51-7.

7 Gibbs JM, Wise RJ, Leenders KL, et al. Evaluation of cerebral perfusion reserve in patients with carotid-artery occlusion. Lancet 1984;i:310-4.

8 Bladin CF, Chambers BR. Frequency and pathogenesis of hemodynamic stroke. Stroke 1994;25:2179-82.

9 Yamauchi H, Fukuyama H, Kimura J, et al. Hemodynamics in internal carotid artery occlusion examined by positron emission tomography. Stroke 1990;21:1400-6.

10 Schomer DF, Marks MP, Steinberg GK, et al. The anatomy of the posterior communicating artery as a risk factor for ischemic cerebral infarction. N Engl f Med 1994;330:1565ischem.

11 Miralles M, Dolz JL, Cotillas J, et al. The role of the circle of Willis in carotid occlusion: assessment with phase contrast MR angiography and transcranial duplex. Eur $\mathcal{f}$ Vasc Endovasc Surg 1995;10:424-30. 
12 Hedera P, Bujdakova J, Traubner P. Effect of collateral flow patterns on outcome of carotid occlusion. Eur Neurol 1995 patterns on

13 Mull M, Schwarz M, Thron A. Cerebral hemispheric low-flow infarcts in arterial occlusive disease. Lesion patterns and angiomorphological conditions. Stroke 1997; 28:118-23.

14 Furst G, Steinmetz H, Fischer H, et al. Selective MR angiography and intracranial collateral blood flow. $\mathcal{f}$ Comput Assist Tomogr 1993;17:178-83.

15 Muller M, Hermes M, Bruckmann H, et al. Transcranial Doppler ultrasound in the evaluation of collateral blood flow in patients with internal carotid artery occlusion: correlation with cerebral angiography. AfNR Am $\mathcal{f}$ Neuroradiol 1995;16:195-202.

16 Baumgartner RW, Mattle HP, Schroth G. Transcranial colour-coded duplex sonography of cerebral arteriovenous malformations. Neuroradiology 1996;38:734-7.

17 Harrison MJG, Marshall J. The variable clinical and CT findings after carotid occlusion: the role of collateral blood findings after carotid occlusion: the role of collateral b

18 The EC/IC bypass study group. Failure of extracranialintracranial arterial bypass to reduce the risk of ischemic stroke. Results of an international randomized trial. N Eng f Med 1985;313:1191-200.

19 Buijs PC, Krabbe-Hartkamp MJ, Bakker CJG, et al. Effect of age on cerebral bloodflow: measurement with ungated two-dimensional phase-contrast MR angiography in 250 adults. Radiology 1998;209:667-74

20 Pelc LR, Pelc NJ, Rayhill SC. Arterial and venous bloodflow: non-invasive quantitation with $\mathrm{MR}$ imaging. Radiology 1992;185:809-12.

21 Bakker CJG, Hartkamp MJ, Mali WPTM. Measuring blood flow by nontriggered $2 \mathrm{D}$ phase contrast $\mathrm{MR}$ angiography. Magn Reson Imaging 1996;14:609-14.

22 van Everdingen KJ, Klijn CJM, Kappelle LJ, et al. MRA flow quantification in patients with a symptomatic internal carotid artery occlusion. Stroke 1997;28:1595-600.

23 Miller BL. A review in chemical issues in $1 \mathrm{H}$ NMR spectroscopy: N-acetyl-L-aspartate, creatine and choline. spectroscopy: N-acetyl-L-aspar

24 Mathews VP, Barker PB, Blackband SJ, et al. Cerebral metabolites in patients with acute and subacute strokes: concentrations determined by quantitative proton MR spectroscopy. AfR Am F Roentgenol 1995;165:633-8.

25 Tallan HH. Studies on the distribution of N-acetyl-Laspartic acid in brain. $\mathcal{F}$ Biol Chem 1957;224:41-5.

26 Urenjak J, Williams SR, Gadian DG, et al. Proton nuclear magnetic resonance spectroscopy unambiguously identifies different neural cell types. F Neurosci 1993;13:981-9.

27 Kuzniecky R, Hetherington HP, Pan J, et al. Proton spectroscopic imaging at 4.1 tesla in patients with malformations of cortical development and epilepsy. Neurology 1997;48: 1018-24.

28 Moore GJ, da Silva EA, Watson C. Normalization of neurochemical abnormalities in the unoperated temporal lobe following neurosurgery for unilateral temporal lobe epilepsy. Proceedings of the International Society of Magnetic Resonance in ceedings of the International Society of Magnetic Resonance in

29 Scremin OU, Jenden DJ. Focal ischemia enhances choline output and decreases acetylcholine output from rat output and decreases acetylcholine

30 Gideon P, Sperling B, Arlien Soborg P, et al. Long term follow up of cerebral infarction patients with proton magnetic resonance spectroscopy. Stroke 1994;25:967-73.

31 Felber S, Aichner F, Sauter R, et al. Combined magnetic resonance imaging and proton MR spectroscopy of patients with acute stroke. Stroke 1992;23:1106-10.

32 Graham GD, Kalvach P, Blamire AM, et al. Clinical correlates of proton magnetic resonance spectroscopy findings after acute cerebral infarction. Stroke $1995 ; 26: 225-9$.

33 North American Symptomatic Carotid Endarterectomy Trial Collaborators. Beneficial effect of carotid endarterectomy in symptomatic patients with high-grade carotid stetomy in symptomatic patients with high

34 Elgersma OEH, van Leersum M, Buijs PC, et al. Changes over time in optimal duplex threshold for the identification of patients eligible for carotid endarterectomy. Stroke 1998; 29:2352-6.

35 van Everdingen KJ, Visser GH, Klijn CJM, et al. Role of collateral flow on cerebral hemodynamics in patients with unilateral internal carotid artery occlusion. Ann Neuro 1998;44:167-76.
36 Bakker CJG, Kouwenhoven M, Hartkamp MJ, et al. Accuracy and precision of time-averaged flow as measured by non-triggered 2D phase-contrast MR angiography: a

37 Bogousslavsky J, Regli F. Borderzone infarctions distal to internal carotid artery occlusion: prognostic implications. Ann Neurol 1986;20:346-50.

38 Bogousslavsky J, Regli F. Unilateral watershed cerebral infarcts. Neurology 1986;36:373-7.

39 Moody DM, Bell MA, Challa VR. Features of the cerebral vascular pattern that predict vulnerability to perfusion or oxygenation deficiency: an anatomic study. AfNR Am f Neuroradiol 1990;11:431-9.

40 Ordidge RJ, Bendall MR, Gordon RE, et al. Volume selection in vivo spectroscopy. In: Govil G, Khetrapal C, Saran A, eds. Magnetic resonance in biology and medicine. New Dehli, India: Tata McGraw-Hill, 1985:387-97.

41 Bottomley PA. Spatial localization in NMR spectroscopy in vivo. Ann N Y Acad Sci 1986;508:333-48.

42 Vanninen $\mathrm{R}$, Koivisto $\mathrm{K}$, Tulla $\mathrm{H}$, et al. Hemodynamic effects of carotid endarterectomy by magnetic resonance flow quantification. Stroke 1995;26:84-9.

43 Van der Grond J, Eikelboom BC, Mali WPTM. Flowrelated anaerobic metabolic changes in patients with severe stenosis of the internal carotid artery. Stroke 1996;27:202632 .

44 Blankensteijn JD, Van der Grond J, Mali WPTM, et al. Flow volume changes in the major cerebral arteries before and after carotid endarterectomy: an MR angiography study. Eur 7 Vasc Endovasc Surg 1997;14:446-50.

45 Davis WL, Turski PA, Gorbatenko KG, et al. Correlation of cine MR velocity measurements in the internal carotid artery with collateral flow in the circle of Willis: preliminary study. F Magn Reson Imaging 1993;3:603-9.

46 Vanninen RL, Manninen HI, Partanen PLK, et al. Carotid artery stenosis: clinical efficacy of MR phase-contrast flow quantification as an adjunct to $\mathrm{MR}$ angiography. Radiology 1995;194:459-67.

47 Levine RL, Turski PA, Holmes KA, et al. Comparison of magnetic resonance volume flow rates, angiography, and carotid Dopplers. Preliminary results. Stroke 1994;25:413-7.

48 van Everdingen KJ, Van der Grond J, Kappelle LJ. Overestimation of a stenosis in the internal carotid artery by duplex sonography caused by an increase in volume flow. 7 Vasc Surg 1998;27:479-85.

49 Norris JW, Krajewski A, Bornstein NM. The clinical role of the cerebral collateral circulation in carotid occlusion. $f$ Vasc Surg 1990;12:113-8.

50 Widder B, Kleiser B, Krapf H. Course of cerebrovascular reactivity in patients with carotid artery occlusions. Stroke 1994;25:1963-7.

51 Derdeyn CP, Videen TO, Fritsch SM, et al. Compensatory mechanisms for chronic cerebral hypoperfusion in patients with carotid occlusion. Stroke 1999;30:1019-24.

52 Stevens H, Jansen HM, De Reuck J, et al. ${ }^{55} \mathrm{Co}-\mathrm{PET}$ in stroke: relation to bloodflow, oxygen metabolism and gadolinium-MRI. Acta Neurol Belg 1997;97:172-7.

53 Derdeyn CP, Yundt KD, Videen TO, et al. Increased oxygen extraction fraction is associated with prior ischemic events in patients with carotid occlusion. Stroke 1998;29:754-8.

54 Powers WJ, Press GA, Grubb RL Jr. The effect of hemodynamically significant carotid artery disease on the hemodynamic status of the cerebral circulation. Ann Intern Med $1987,106: 27-35$

55 Bakker CJG, Hoogeveen RM, Viergever MA. Construction of a protocol for measuring blood flow by two-dimensional phase contrast MRA. F Magn Reson Imaging 1999;9:119-27.

56 Evans AJ, Iwai F, Grist TA, et al. Magnetic resonance imaging of blood flow with a phase subtraction technique. In vitro and in vivo validation. Invest Radiol 1993;28:109-15.

57 Spritzer CE, Pelc NJ, Lee JN, et al. Rapid MR imaging of blood flow with a phase-sensitive, limited-flip-angle, gradient recalled pulse sequence: preliminary experience. Radiology 1990;176:255-62.

58 Tarnawski $M$, Padayachee $S$, West DJ, et al. The measurement of time-averaged flow by magnetic resonance imaging using continuous acquisition in the carotid arteries and its comparison with Doppler ultrasound. Clin Phys Physiol Meas 1990;11:27-36.

59 Tang C, Blatter DD, Parker DL. Accuracy of phase-contrast flow measurements in the presence of partial-volume effects. Magn Reson Imaging 1993;3:377-85. 